\title{
Crunch time for the government on alcohol pricing in England
}

\author{
Backtracking on the minimum unit price pledge would be a public health disaster
}

\author{
Gabriel Scally director \\ WHO Collaborating Centre for Healthy Urban Environments, University of the West of England, Bristol BS16 1QY, UK
}

Last week, David Cameron was questioned in parliament on a claim that the forthcoming budget speech would be used to announce that the government would not be implementing a minimum price per unit of alcohol in England. ${ }^{1}$ If the prime minister does not implement his pledge to introduce a minimum unit price for alcohol it will be not be just a policy U-turn but a wilful disregard for the health and wellbeing of the English population. According to the figures quoted in the government's own alcohol strategy published in 2012, there were almost one million alcohol related violent crimes and 1.2 million alcohol related hospital admissions in 2010-11 alone. ${ }^{2}$ In its written evidence to the 2012 Health Select Committee, the Department of Health estimated the total costs of alcohol misuse in England at about £21bn (€24.5bn; $\$ 31.8$ bn) a year. ${ }^{3}$

Controlling the price and availability of alcohol has always been the way for policy makers to reduce harms related to alcohol consumption. This policy goes back at least as far as the English gin craze of the 18 th century. ${ }^{4}$ Because alcohol misuse is one of the top three threats to public health, alongside tobacco use and obesity, firm action is needed to reduce the cost of alcohol to individuals and families, the NHS, and a country struggling with austerity.

David Cameron's personal, signed foreword to the alcohol strategy published in March 2012 was blunt and clear: "When beer is cheaper than water, it's just too easy for people to get drunk on cheap alcohol at home before they even set foot in the pub. So we are going to introduce a new minimum unit price." This firm commitment was repeated in November 2012 in the consultation document issued by the Home Office and in which views were invited on the level at which the unit price would be set. ${ }^{5}$

The case for change has been well made and the last chief medical officer of England advocated the introduction of minimum unit pricing in his 2008 annual report. ${ }^{6}$ The evidence base for minimum unit pricing is also very clear. Modelling shows that the imposition of a minimum price per unit would affect consumption among harmful drinkers far more,

proportionately, than it would among moderate drinkers. ${ }^{7}$ The Home Office's impact assessment shows that a minimum price of 45p per unit of alcohol would result in average annual savings to the NHS of $£ 220 \mathrm{~m}$ a year during the 10 years after its introduction. By the end of this 10 year period 714 deaths and 24600 hospital admissions would be prevented annually. ${ }^{8}$ The additional cost to moderate drinkers would be minimal, and it would probably move the balance in alcohol sales away from the "off trade," particularly supermarket sales, back towards the more regulated environment of pubs and bars, which has been in decline in recent years.

The alternative and more traditional approach of increasing the tax on alcohol will not achieve the same ends because of the aggressive price cutting and promotional approaches used by supermarkets to achieve and maintain their domination in the market place. What's more, there is now clear evidence from Canada that minimum unit pricing works in practice. ${ }^{9}$ Analysis of the effects of alcohol pricing changes in three Canadian provinces showed that a $10 \%$ increase in minimum price reduced consumption of affected alcoholic drinks by $16.1 \%$ relative to all other drinks.

We are in a crucial phase for public health in England. A surge in non-communicable diseases threatens to swamp the NHS. Firm leadership is needed now more than ever. However, it seems that the government has fallen under the malign spell of the very industries whose power and influence need to be curbed if we are to improve population health and prevent the NHS being overburdened. The vested interests of the alcohol and food industries have dominated the Department of Health's responsibility deals on alcohol and food. Industry has campaigned hard against minimum pricing of alcohol, fought the implementation of plain packaging of tobacco, and delivered the horsemeat scandal. If the prime minister reneges on his crystal clear policy pledge on alcohol we will all know whose interests he truly serves.

Competing interests: I have read and understood the BMJ Group policy on declaration of interests and declare the following interests: GS was employed by the Department of Health until April 2012.

Provenance and peer review: Commissioned; not externally peer reviewed. 
1 David Cameron vows to end cheap alcohol sales. BBC News 2013 March 13. www.bbc. co.uk/news/uk-politics-21766309.

2 HM Goverment. The government's alcohol strategy. 2012. www.homeoffice.gov.uk publications/alcohol-drugs/alcohol/alcohol-strategy?view=Binary.

3 House of Commons Health Committee. Third report: government's alcohol strategy. 2012. www.publications.parliament.uk/pa/cm201213/cmselect/cmhealth/132/132.pdf.

4 Dillon P. Gin: the much-lamented death of Madam Geneva. Justin Charles, 2002.

5 Home Office. A consultation on delivering the government's policies to cut alcohol fuelled crime and anti-social behaviour. 2012. http://homeoffice.gov.uk/publications/about-us/ crime and anti-social behaviour. 2012. http://homeoffice.gov.uk/publications/about-u
consultations/alcohol-consultation/alcohol-consultation-document?view=Binary.

6 Donaldson L. 150 years of the annual report of the chief medical officer: on the state of public health 2008. Department of Health, 2009. www.dh.gov.uk/en/ Publicationsandstatistics/Publications/AnnualReports/DH_096206.
7 Meier PS, Purshouse R, Brennan A. Policy options for alcohol price regulation: the importance of modelling population heterogeneity. Addiction 2010;105:383-93.

8 Home Office. A minimum unit price for alcohol. Impact assessment. 2012. www.homeoffice. gov.uk/publications/about-us/consultations/alcohol-consultation/ia-minimum-unit-pricing? view=Binary.

9 Stockwell T, Auld MC, Zhao J, Martin G. Does minimum pricing reduce alcohol consumption? The experience of a Canadian province. Addiction 2012;107:912-20.

Cite this as: BMJ 2012;346:f1784

(c) BMJ Publishing Group Ltd 2013 